\title{
First report of hovering guard bees of the Paleotropical stingless bee Tetrigona apicalis (Hymenoptera: Apidae: Meliponini)
}

\author{
Michael Burgett ${ }^{1}$, Panuphan Sangjaroen ${ }^{2}$, Janjira YAvilat $^{2}$, Bajaree Chuttong $^{3}$ \\ ${ }^{1}$ Department of Horticulture, Oregon State University, Corvallis, OR 97331, USA \\ ${ }^{2}$ Department of Entomology and Plant Pathology, Chiang Mai University, Chiang Mai 50200, Thailand \\ ${ }^{3}$ Science and Technology Research Institute, Chiang Mai University, Chiang Mai 50200, Thailand
}

Received 2 April 2019 - Revised 27 September 2019 - Accepted 7 November 2019

\begin{abstract}
For eusocial bees, colony defense is paramount. An uncommon strategy is the deployment of hovering guard bees, which has been previously described for only a few species of Neotropical meliponines. This report describes the use of flying guards for the Paleotropical stingless bee species Tetrigona apicalis (Smith) which is the first known species in the region to incorporate this defense strategy. The first appearance of hovering guards occurs ca. 0800 , and the number of guards increases until an assemblage of ca. several to 25 guards is formed within an hour of the first appearance of a flying guard. The cloud of hovering guards remains throughout the day until dusk and has a continuous presence unless interrupted by rain. The group hovers in front of the entrance tube out to a distance of 10 to $35 \mathrm{~cm}$ with the guards facing the entrance tube. The length of time an individual hovering guard bee spends in flight averaged $17 \mathrm{~min} 52 \mathrm{~s} \pm 18 \min 2 \mathrm{~s}$. The longest hovering flight was $1 \mathrm{~h} 48 \mathrm{~min} 46 \mathrm{~s}$. This compares to a reported guard flight time of ca. $58 \mathrm{~min}$ for the Neotropical meliponine Tetragonisca angustula, the only other stingless bee species where flying guard flight times have been investigated.
\end{abstract}

\section{flying guard bees / Tetrigona apicalis / length of hovering flight}

\section{INTRODUCTION}

Meliponini (stingless bees) are the largest taxon of social bees with known 556 described species (Rasmussen and Gonzalez 2013). For social bees, colony defense is paramount, and stingless bees have evolved numerous strategies to protect nests from predators and parasites. Various stingless bee nest defenses are reviewed by Roubik (2006). An infrequent defense mechanism is the incorporation of aerial guard bees, and only a few stingless

Corresponding author: M. Burgett, michael.burgett@oregonstate.edu Handling Editor: Peter Rosenkranz bee species are known to utilize this strategy. Two Neotropical species, Tetragonisca angustula Latreille and Tetragona clavipes F., are known to employ flying guards (Roubik 2006; Wittmann 1985; Zeil and Wittmann 1989). The Paleotropical stingless bee Tetragonula carbonaria Smith is known to utilize defensive swarms during usurpation and robbing events that are reported to last for days or even weeks (Gloag et al. 2008), but this is separate from employing a continuous group of hovering guards.

Of the ca. 90 described stingless bee species in SE Asia (Rasmussen 2008), none has been reported to employ a permanent flying guard bee cadre. The result of an intensive literature review fails to find any previous mention of the use of flying guards by $T$. apicalis; therefore, this is the first 
declaration of the phenomenon for this species. Tetrigona apicalis was first described by Smith (1857) as Trigona apicalis from material originally provided by A.R. Wallace from Borneo. The species is widely distributed throughout its SE Asian and Indo-Malayan/Australasian range (Rasmussen 2008). T. apicalis is a mediumsized bee with bicolorous wings and a body length of 5.5-6 mm. T. apicalis nests normally occupy tree cavities but they are known to advantageously utilize anthropogenic cavities, i.e., wall voids (Burgett, personal observation). T. apicalis nest entrance tubes are stereotypically elongate and in the form of a flattened trumpet bell. In mature colonies, entrance tubes are ca. 15 to $25 \mathrm{~cm}$ in length and comprised almost entirely of hardened plant resins. The Neotropical species Tetragonisca angustula is known to use both flying guards and stationary guards immediately inside and outside of the nest entrance tube. These separate groups of both stationary guards just interior to the nest entrance and the hovering guards are felt to complement each other (Karcher and Ratnieks 2009; Grüter et al. 2011) in intruder defense and recognition of conspecific nest mates. Guards of T. angustula have been shown to be morphologically distinct from forger bees and are designated as a specialized major caste (Grüter et al. 2012).

The length of hovering flight time for guard bees has been inadequately addressed. Wittmann (1985) discussing Tetragonisca angustula states that labelled guards were observed hovering for more than 70 min. Grüter et al. (2011) also reporting on T. angustula state an average hovering time of $56.7 \pm 1.51$ min. Additionally, they comment that individual flying guards interrupt their flight with a 3.3-min hive return before recommencing flight. Our work reports on hovering flight times of $T$. apicalis guards as observed in Northern Thailand.

\section{MATERIALS AND METHODS}

One of the $T$. apicalis colonies used for observations was recovered from a discarded armoire that had been thrown from a 2nd story dormitory balcony on the Chiang Mai University campus (Chiang Mai province, Northern
Thailand) in mid-January of 2018. We rehoused the colony into a wooden domicile with an internal volume of $26.46 \mathrm{~L}$ and kept it in situ on the dormitory balcony for 7 days allowing the bees to readjust to the new nest cavity. The colony was then relocated in the evening to a meliponary adjacent to the Chiang Mai University Postharvest Technology Research Center ca. $2 \mathrm{~km}$ from its original location. At this location were an additional 10 stingless bee colonies composed of Tetragonula laeviceps (Smith), Tetragonula fuscobalteata (Cameron), and Lepidotrigona flavibasis (Cockerell). The T. apicalis colony was placed on a stand at a height of $25 \mathrm{~cm}$ above ground level. A single 5-mm diameter hole, $10 \mathrm{~cm}$ from the base of the domicile, provided the only ingress/egress for the bees. The morning following relocation, the colony recommenced foraging flights and flying guards appeared $24 \mathrm{~h}$ later. As this colony had undergone the trauma of dislocation and rehousing, the number of flying guard bees was initially quite small (1-3 individual bees) and the construction of an entrance tube took several months. For our observation in January of 2019, an entrance tube ca. $6 \mathrm{~cm}$ in length had been formed. This turned out to be quite advantageous as tracking individual guard flights was made easier because of the reduced number of flying guards. No attempt was made to tag the individual guards.

To assess flying guard flight times, we initiated a video record using a GoPro 1080P sports camera set ca. $40 \mathrm{~cm}$ from the nest entrance with a visual field of ca. $75 \times 75 \mathrm{~cm}$ parallel to the side of the colony. White cardboard panels were set $1 \mathrm{~m}$ opposite the camera view to facilitate viewing guard bee flight. Flight video records of the hovering guards were undertaken in February and March of 2018 and January of 2019. Daily videos commenced at $0800 \mathrm{~h}$ and ceased at $1700 \mathrm{~h}$ during 13 non-contiguous days of observation. As a quality check, every 10th flight time was recalculated by a second observer.

Two additional $T$. apicalis colonies nesting in situ in tree cavities (Ficus religiosa L.) were used for observations concerning guard hovering behavior. 

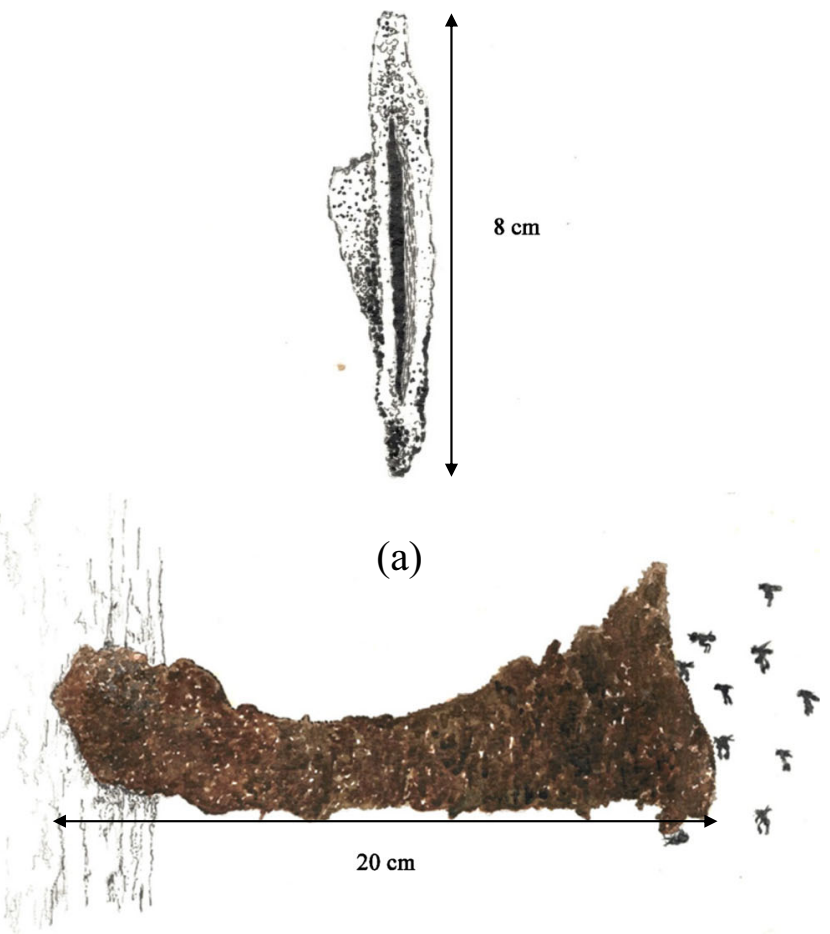

(b)

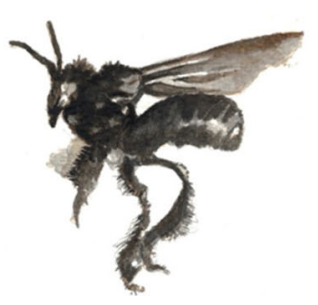

(c)

Figure 1 Bio-illustration of a stereotypic Tetrigona apicalis nest entrance. a Nest entrance front view. b Nest entrance side view with hovering guard bees. $\mathbf{c}$ Flight posture of a hovering guard.

\section{RESULTS}

During diurnal flight periods, a cadre of several to 25 flying guard bees hovers $10-35$ $\mathrm{cm}$ in front of and to the sides of the entrance tube opening, oriented with their heads facing the nest entrance. This cloud of hovering guards is slow moving and can shift both laterally and vertically. Individual hovering guards will move short distances in response to the exit and return of forager bees. Figure 1 illustrates a stereotypic colony entrance.

Figure 2 displays the observed flights classed by 10 -min intervals. Eighty percent of observed flights were between 1 and $30 \mathrm{~min}$ in length. Seven of the 203 observed flights $(3.4 \%)$ were greater than $1 \mathrm{~h}$ with the longest flight at $1 \mathrm{~h} 48 \mathrm{~min}$ $46 \mathrm{~s}$. The average length of flight was $17 \mathrm{~min} 52 \mathrm{~s} \pm 18 \mathrm{~min} 2 \mathrm{~s}$ (SD). Hovering flights of $\leq 1 \mathrm{~m}$ were not included in 


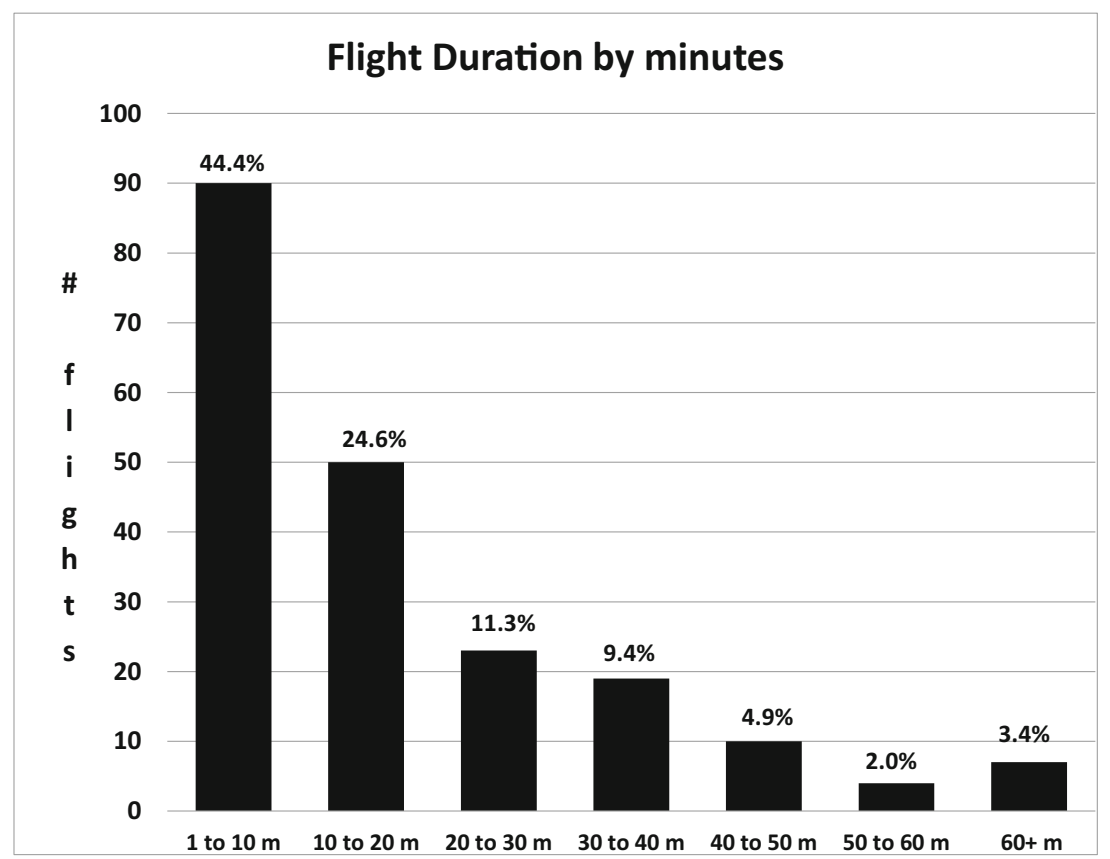

Figure 2 Hovering Tetrigona apicalis aerial guard flights classed by $10-\min$ periods. Percent of total flights $(n=$ 203).

determining the average flight time as these could have been new forager orientation flights. Figure 3 displays all observed flights in a scatter plot from the shortest to the longest flight.

\section{DISCUSSION}

The use of flying guards must certainly be energetically expensive for a stingless bee colony and is only known to occur in a small

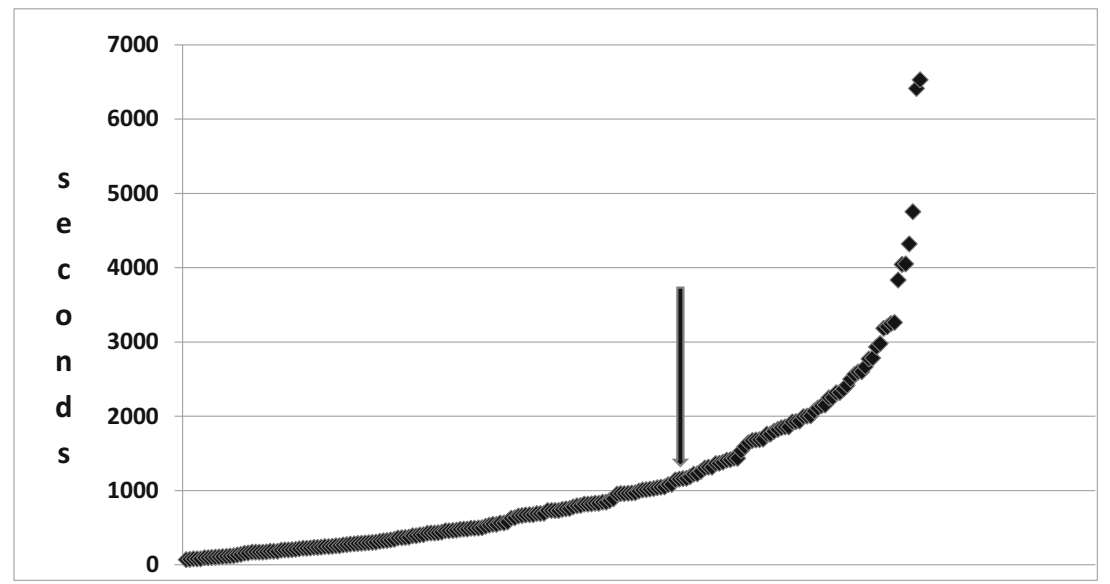

Figure 3 All hovering flights from the shortest to the longest in seconds $(n=203)$. Arrow denotes average flight time (1072 s). 
number of the ca. 560 described meliponine species. The question arises as to efficacy of this defense strategy. The best studied species of the meliponines utilizing flying guards is Tetragonisca angustula. Van Zweden et al. (2011) in a review of the multiple defense mechanisms of $T$. angustula hypothesized that predation by conspecifics and allospecifics, especially the obligate robber stingless bee Lestrimelitta limao (Smith), has brought about, as they state, "... one of the most sophisticated guarding systems known amongst social bees." The 56.7-min average hovering time of $T$. angustula flying guards reported by Grüter et al. (2011) is three times the length of $T$. apicalis hovering guard flights (17 min $52 \mathrm{~s}$ ) that we report here. Our flight time observations come from a single colony that had undergone the stress of being rehived and relocated, which in all likelihood reduced the adult bee population. That said, the colony demonstrated foraging activity and the appearance of a small group of flying guards within $24 \mathrm{~h}$ of relocation which we believe is an accurate reflection of normal colony behavior.

In our $104 \mathrm{~h}$ video record of $T$. apicalis, we never observed a defensive response by a hovering guard bee even though numerous instances were seen where allospecifics, most often Tetragonula laeviceps, flew within centimeters of the nest entrance in the presence of hovering guards. We did not see however any instance where an allospecific attempted to enter the colony itself, which may account the lack of a defensive response on the part of $T$. apicalis aerial guards. We were unable to identify stationary guard bees just interior to the nest entrance in observations of two additional T. apicalis colonies suggesting that this species would appear to rely on hovering guards as the main nest entrance defense strategy.

Grüter et al. (2012) have shown that the stationary and flying guards of $T$. angustula differ in weight and morphology from foragers and designate the guards as a distinct physical caste. Previous to the work of Grüter et al., one could assume that guarding is part of a temporal polyethism continuum. Whether such is the case with T. apicalis is unknown but very worthy of further investigation.
No specialist predators of $T$. apicalis are reported from the limited literature on this species. It remains unclear as to why this singular SE Asia meliponine has evolved a flying guard bee defense, and we anticipate further studies to clarify the role of T. apicalis aerial guards

\section{ACKNOWLEDGMENTS}

We thank Ms. Nadchawan Charoenlertthanakit of the Chiang Mai University Department of Landscape Design for permission to use her art work (Figure 1). We also thank Ms. Lakkhika Panyaraksa from the Science and Technology Research Institute for her assistance in providing biometric data.

\section{AUTHORS' CONTRIBUTION}

$\mathrm{MB}$ and $\mathrm{BC}$ conceived the research. PS and JY performed the bulk of the observations and video review of flight times and interpretation of data. $\mathrm{MB}$ and $\mathrm{BC}$ wrote the first draft and all authors contributed in manuscript revisions. All authors read and approved the final manuscript.

\section{COMPLIANCE WITH ETHICAL STANDARDS}

Conflict of interest The authors declare that they have no conflict of interest.

Premier signalement d'abeilles gardienne pour Tetrigona apicalis (Hymenoptera : Apidae : Meliponini).

abeilles volantes de garde / Tetrigona apicalis / durée du vol stationnaire.

Ein erster Bericht von Wächterbienen der stachellosen Biene Tetrigona apicalis (Hymenoptera: Apidae: Meliponini).

Fliegende Wächterbiene / Tetrigona apicalis / Länge des Wächterfluges. 


\section{REFERENCES}

Gloag, R., Heard, T.A., Beekman, M., Oldroyd, B.P. (2008) Nest defence in a stingless bee: what causes fighting swarms in Trigona carbonaria (Hymenoptera, Meliponini)? Insect. Soc. 55(4): 387-391.

Grüter, C., Karcher, M.H., Ratnieks, F.L.W. (2011) The natural history of nest defence in a stingless bee Tetragonisca angustula (Latreille) (Hymenoptera: Apidae) with two distinct types of entrance guards. Neotrop. Entomol. 42(1), 55-61.

Grüter, C., Menezes, C., Imperatriz-Fonseca, V.L., Ratnieks, F.L. (2012) A morphologically specialized soldier caste improves colony defense in a neotropical eusocial bee. P. Natl. Acad. Sci USA 109, 1182-1186.

Karcher, M.H., Ratnieks, F.L.W. (2009) Standing and hovering guards of the stingless bee species Tetragonisca angustula complement each other in entrance guarding and intruder recognition. J. Apic. Res. 48(3), 209-214.

Rasmussen, C. (2008) Catalog of the Indo-Malayan/Australasian stingless bees (Hymenoptera: Apidae: Meliponini). Zootaxa 1935. 80 pages.

Rasmussen, C., Gonzalez, V.H. (2013) Prologue. Stingless bees now and in the future. pp vi-ix. In: Vit, P., Roubik, D.W., eds. Stingless Bees Process Honey and Pollen in
Cerumen Pots. Faculta de Farmacia y Bioanálisis, Universidad de los Andes, M rida, Venezuela.

Roubik, D.W. (2006) Stingless bee nesting biology. Apidol. 37, 124-143.

Smith, F. (1857) Catalogue of the hymenopterous insects collected at Sarawak, Borneo; Mount Ophir, Malacca; and at Singapore, by A.R. Wallace. J. Proceed. Linn. Soc. London, Zool. 2, 42-88.

Van Zweden, J.S., Gruter, C., Jones, S.M., Ratnieks, F.L.W. (2011) Hovering guards of the stingless bee Tetragonisca angustula increase colony defensive perimeter as shown by intra- and inter-specific comparisons. Behav. Ecol. Sociobiol. 65(6), 1277-1282.

Wittmann, D. (1985) Aerial defense of the nest by workers of the stingless bee Trigona (Tetragonisca) angustula (Latreille) (Hymenoptera: Apidae). Behavior. Ecol. Sociobiol. 16(2), 111-114.

Zeil, J., Wittmann, D. (1989) Visually controlled stationkeeping by hovering guard bees of Trigona (Tetragonisca) angustula (Apidae, Meliponinae). J. Comp. Physiol. A. 165, 711-718.

Publisher's note Springer Nature remains neutral with regard to jurisdictional claims in published maps and institutional affiliations. 